\title{
A Competência e a Hierarquia como Pressupostos do Regime Disciplinar
}

CORSÍNDIO MONTEIRO DA SILVA

Assistente Jurídico do DASP

O capítulo Do regime disciplinar, constante do Estatuto dos Funcionários Públicos Civis da União, cuida dos deveres dos servidores públicos para com o Estado como Administração Pública, capítulo esse considerado um dos mais importantes daquele diploma legal "porque em seu bojo se reúnem os princípios constitutivos do chamado Direito Disciplinar".1

Vejamos algumas noções básicas sobre os fundamentos do regime disciplinar.

Sabemos que Administração Pública é um complexo orgânico regido por relações de dependêcia que se realizam no direito de o órgão superior dar instruções e no dever de o órgão dependente ou inferior obedecê-las.

Emerge, daí, como se vê, uma relação de dependência: um, tem o direito de dar instruções, de dar ordens, que é o órgão superior; outro, tem o dever de obedecer, que é o órgão subalterno ou inferior.

São funções essas divididas por graus e por competência legal que atuam dentro do princípio de subordinação do inferior ao superior. É o que se chama hierarquia.

A hierarquia é da essência da administração, seja ela qual for. Tanto é assim que a quebra de suas regras implica numa sanção.

A disciplina é uma decorrência da hierarquia.

De tanta e tamanha relevância é a hierarquia quanto a disciplina no Serviço Público, que já se cogita de dar autono-

1 CARVALHO, A.A. Contreiras de - Estatuto dos Funcionários Interpretado, II, 3ạ ed., Freitas Bastos, Rio-São Paulo, 1964, pág. 71. 
mia a um ramo do Direito Público Interno com o nome de Direito Disciplinar, direito esse ligado à idéia de poder disciplinar, de autoridade disciplinar. Vale dizer, intimamente ligado à idéia de hierarquia. ${ }^{2}$

Hierarquia é comumente entendida como o princípio da disciplina que está, tanto na base do complexo sistema da função pública, institucionalmente considerada e ordenada, quanto na relação existente entre o órgão superior e o órgão a ele subordinado, ou inferior.

Hierarquia seria, então, na definição de Baldi Papini, a relação de supremacia dos órgãos superiores com relação aos órgãos inferiores e, por fim, a relação de subordinação em que se encontram os órgãos inferiores relativamente a seus supe-
riores. $^{3}$

Já Hauriou ${ }^{4}$ define a hierarquia como uma superposição de graus em uma organização autoritária de agentes, de tal modo que os agentes inferiores não executam suas funções em virtude de uma obrigação direta e única de observar a lei, senão pela obrigação de obedecer a seu chefe que se interpõe entre ele e a lei.

Donde se infere que o dever primeiro é o de obediência hiearárquica, representando o superior hierárquico a expressão

A doutrina italiana sustenta que, em sentido amplo, hierarquia significa escala de valores, dentro de um sentido de competência legal e de estratificação de competências. Há uma presunção legal de que o que está acima, hierarquicamente, representa um valor mais alto, embora se saiba que, na realiraro, é tica, nem sempre isto é verdadeiro. Mas a verdade, não

De convenção. De modo que o exercício do poder hierárquico pressupõe
esse vínculo de subordinação. E deste vínculo de subordinação surge o dever de obedecer para aquele que está num degrau
hierárquico inferior.

Surge, então, para o órgão dependente ou inferior, o dever de obedecer as instruções ou ordens advindas do órgão hie-
rarquicamente superior.

2 CAVALCANTI, Themistocles Brandão - Direito e Processo Disciplinar; 2 ed., F. G. V., Rio, 1966, p. 76

3 II rapporto d'impiego 1966, p. 76. 1933 , p. 77

Prècis padua, 1942, p. 9. 
Assim é toda a organização estatal dentro do Estado burocrático.

Daí dizer Fritz Fleiner que, entre as características do Estado burocrático, se encontra a estreita dependência, por parte dos funcionários administrativos, em relação às autoridades superiores, uma vez que, a despeito da multiplicidade de cargos, fica salvaguardada a unidade da vontade do Estado que age por meio da Administração, o que se consegue pelo controle dos serviços e pelo dever de obediência: a subordinação. Todos os funcionários - continua o Mestre - são órgãos que integram uma mesma pessoa jurídica, que se chama Estado, e estão hierarquicamente classificados em superiores e subordinados. A vontade do Estado é tanto maior, tanto mais forte e autêntica, quanto mais alto se encontra o órgão que a manifesta: é no órgão supremo do Estado que essa vontade se caracteriza com maior vigor e autenticidade. Daí porque, para um subordinado, a vontade da instância superior resulta mais forte e mais perfeita quanto ao interessado do que a vontade da instância inferior. Por este motivo, são as autoridades administrativas superiores os órgãos naturais aos quais incumbe apreciar os recursos. Interposto um recurso, têm aquelas autoridades o dever de lhe dar solução adequada. As autoridades superiores, por isso mesmo, são as competentes para prescreverem aos subordinados, mediante ordens de serviço, uma certa conduta, ou para anularem de ofício as decisões das autoridades inferiores, caso sejam essas decisões contrárias à lei ou ao interesse público. De modo que o funcionário está obrigado, em virtude de sua subordinação, a obedecer às ordens ditadas pelo superior dentro da esfera de sua competência. ${ }^{5}$

A quebra de tais regras implica numa sanção pois que
fere a disciplina.

A ação disciplinar está praticamente sujeito todo o funcionalismo público, naquilo que se refere às relações de dependência entre o Estado e o seu agente.

E essa subordinação decorre, precisamente, do sistema hierárquico.

Assim é que, aquele que estiver sujeito à subordinação hierárquica, pode sofrer o efeito do poder disciplinar. ${ }^{6} \mathrm{E}$ essa subordinação começa a partir da posse - segundo Marcello Caetano - extingue-se com o término da relação de dependência e de serviço, a que acrescenta Themístocles Brandão 5 FLEINER, Friiz - Instituciones de Derecho Administrativo, Madrid,
Barcelona, Buenos Aires, Ed. Labor, 1933, p. 79.

6 CAVALCANTI, Themistocles Brandão - Op. cit., p. 27. 

Cavalcanti: cessa, também, quando se transfere o funcionário
de um serviço para outro. ${ }^{7}$

Daí se conclui que o superior hierárquico é o legalmente competente para aplicar a pena disciplinar, competência essa que se desenvolve dentro dos diversos graus de hierarquia, conforme a gravidade da falta, por conseguinte, de acordo com a gravidade da pena. Esse o motivo por que se costuma dizer que o poder disciplinar decorre, essencialmente, da posição hierárquica, da qual emana a autoridade para impor a pena. ${ }^{8}$

Estes poderes e estes deveres - poder hierárquico, dever de obediência, poder disciplinar - estão determinados ou regulamentados por normas de direito objetivo ditadas em razão do interesse coletivo, em razão do interesse público... Sem qualquer referência ao interesse individual, razão por que não criam direitos subjetivos. $O$ superior hierárquico que não exercer o poder hierárquico que detém, que não puser em prática seu poder de supremacia ou de ascendência, será, também ele, passivel de sanção. O hierarquicamente inferior que, dentro de certas condições, faltar ao dever de obediência, ou exceder-se dade administrativa, não raro, também, em responsabilidade
civil ou mesmo em responsabilidade penal.

Conforme, assim, a natureza das transgressões, a responsabilidade do servidor público pode ser administrativa, civil e Administração Pública, em face do regime disciplinar e que o torna passivel de uma sanção disciplinar. Ocorre quando, por exemplo, o servidor, no exercício de suas funções, pratica ato ou incorre em omissão que viole as atribuições ou deveres estabelecidos para execução das tarefas, serviços ou encargos que the são cometidos, ou que, mesmo fora de serviço, pratique cionário público. Nesse caso, a sanção atinge o servidor como tal, em sua condição e em seus direitos funcionais. Se o fato ponderá o funcionário perambém, crime contra a Administração, resmente responsável, orante a Justiça comum como penalsua ação ou omissão responderá, ele, tambémultou dano ou prejuízo para o Erário, os cofres públicos (resm, civilmente, para o fim de indenizar

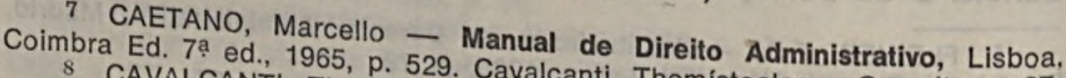
8 CAVALCANTI, Themisto 29. Cavalcanti, Themístocles - Op. cit., p. 27. 
A hierarquia pode significar não somente a existência de numerosos graus de jurisdição, mas pode, igualmente, significar a distribuiçã̃o de competência na esfera administrativa. ${ }^{9}$

$\mathrm{Na}$ definição de MARCELLO CAETANO, competência é um conjunto de poderes que o órgão possui para exercer direitos subjetivos e atribuições da pessoa jurídica. ${ }^{10}$ Tais poderes não pertencem aos indivíduos, mas aos órgãos. São simples modos de exercício dos direitos subjetivos e de outros poderes da pessoa jurídica. Chamam-se, por isso, poderes funcionais. Acentua o ilustre Mestre do Direito Administrativo que os órgãos, em certas matérias, podem não ter competência administrativa própria e estar dependentes, no que se refere ao exercício de poderes administrativos, de outros órgãos da pessoa jurídica por dependência hierárquica que é o modo normal da relação entre os agentes e os órgãos com quem colaboram.11

De modo que, aqui, os caminhos se cruzam: a competência e a hierarquia, daí por que se considera a delimitação da competência como em razão da matéria, em razão do tempo, em
razão do lugar e em razão do grau hierárquico.

Dessa regra, de que a competência do superior compreende a dos subalternos, excetuam-se os casos em que a lei especifique a competência própria dos subalternos, a estes reservando o seu exercício em termos expressos ou de maneira que, claramente, se deduza que desejou efetivamente estabelecer uma distribuição de poderes e ordenar um processo de modo a acautelar ou garantir os direitos dos administrados. ${ }^{12}$ Estão nestes casos - exemplifica Marcello Caetano - os preceitos que permitem a aplicação de sanções pelo subalterno com recurso para o superior, pois a preterição da ordem hierárquica equi-
valoria à supressão de um grau de jurisdição. ${ }^{13}$

Isso tem sido entendido em termos entre nós, na esfera administrativa, para questões de que não resulta aplicação de penalidade, ao se distanciar um tanto dos excessos jurídicos de certas formalidades que servem, não poucas vezes, para acobertar o uso abusivo do direito de pedir, para efeito meramente procastinatório, muitas vezes, em casos de tranqüilo entendimento sobre determinado assunto de controvérsia superada. Insistir todos aqueles que tem igual pretensão na mesma

\footnotetext{
9
10 Op. cit., p. 166 Themístocles Brandão - Op. cit., p. 25.

11 Op. cit, p. 166.

12 CAETANO, Marcello - Op. cit. p. 166.
} 
tecla e dentro do mesmo andamento processual é antieconômico, injusto e danoso para a Administração. Assim, a autoridade administrativa, em certos casos de insistentes pedidos de reconsideração e recurso, recebe o primeiro e o indefere, enviando-o, a seguir, à autoridade superior - na hipótese, o Presidente da República - com exposição de motivos, como se recurso fosse e propõe se the negue provimento, fulminando, assim, uma prática abusiva que vem emperrando a Administração. Exemplo concreto que se poderia dar nesse sentido é o caso específico de certas acumulações de cargos públicos.

Essa prática não há de ser tão injusta, como se pretende, quando se suprime, na esfera do Judiciário, oportunidade de recurso ou de reexame de determinado caso em circunstâncias diversas da decisão tipo, substanciada nas Súmulas, que nem próprio representam o pensamento tranqüilo e uniforme do efeito, quase Judiciário. Para evitar a querela infindável de as ações em detrime, meramente procrastinador, para eternizar alto Tribunal, fechouto da Justiça, o Judiciário, pelo seu mais exaustivo dos processos, suprimindo um dique no andamento tura cartorária de explor, suprimindo etapas e evitando a avenúltimas conseqüências.

Inegavelmente que o princípio de que a autoridade superior deve ater-se a seus limites de competência sem invadir a área de competência do subalterno é altamente salutar e representa uma garantia de direitos. Garantia porque o interessado pode, talvez, oferecer novos elementos de convicção, novos argumentos, e ver o seu processo examinado por outra autoridadéias quase sempre distanciada do ambiente carregado de isenta, conseqüentas e de paixões, podendo ser, assim, mais

Insistimos, entanto, em dizer que se a autoridade superior autoridade que lhe está em grau hierarquicamente inferior, e rece norme a natureza do assunto, isto é, do ilícito, não nos parece ilegítimo que aquela autoridade aplique a penalidade de
menor tência específica e, sim mente.

A rigor, a nosso ver, a garantia de direitos reside mais na nossibilidade do recurso hierárquico que não deve ser negado no Estado de Direito, porém não a absorção pela autoridade 
maior, em certos casos, da competência da autoridade hierarquicamente menor quando esta competência está compreendida na do superior hierárquico.

Por derradieiro, é de se indagar a que nos conduz a hierarquia? Permite ela que uma grande massa de agentes ou servidores públicos pertencentes aos vários serviços administrativos de uma pessoa jurídica, de um Ministério, por exemplo, proceda com unidade, assegurando o comando único concentrado no órgão superior, isto é, no superior que, dentro daquela jurisdição, não é subalterno de ninguém - o Ministro de Estado no seu Ministério, o Presidente da Autarquia na sua Autarquia, o Reitor na sua Universidade. Quando o órgão supremo administrativo é assistido, assessorado ou coadjuvado por agentes subalternos que possuem o poder de praticar atos definitivos e executórios, diz-se que a administração está desconcentrada tralizada. É esto usada por Marcello Caetano - ou está descenAdministrativa. Matéria esta objetivos básicos da nossa Reforma com o recurso de delegação de de descentralização hierárquica de difícil aplicação para resultados juência - que nos parece contrariando certos princípios bados justos se não mesmo que e que seria conveniente resguardar. competência poderá ter efoitorar. A excessiva delegação de va concentração de pee tão negativos quanto a excessi$\mathrm{Na}$ prática recente já deres e atribuições num comando único. ráter absoluto à descentralizanou a inviabilidade de se dar cacia que produziu, malgrado so de autoridade que rado o pretendido originariamente, abução antes que produzissejou a suspensão imediata da delegadade por desnecessidade mal maior. Foi o caso da disponibilisionou injustiças para Administração, configurando, algum para a finalidade. 


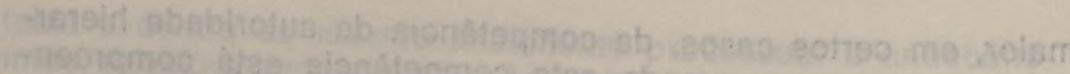

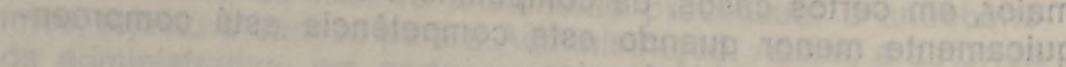

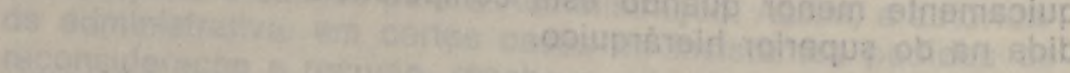

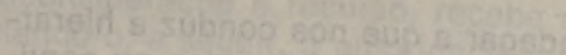

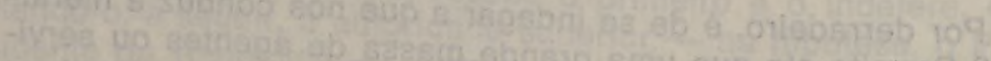

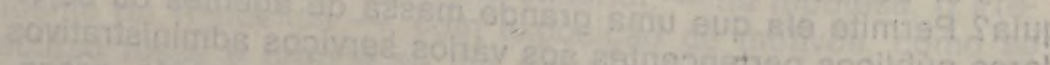

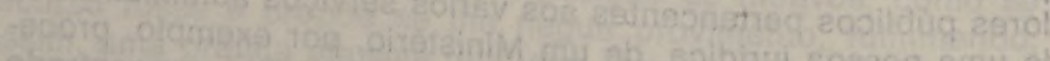

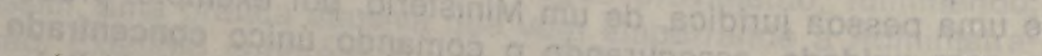

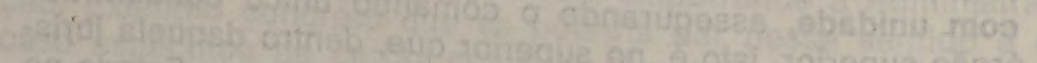

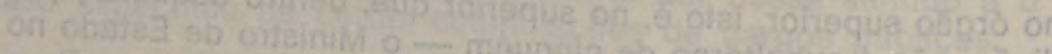

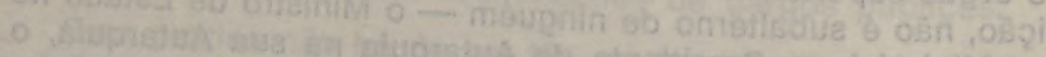

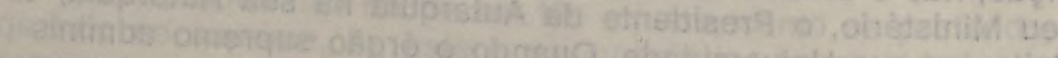

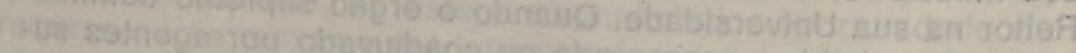

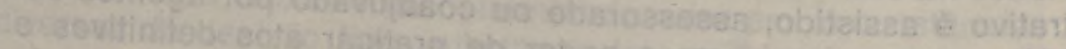

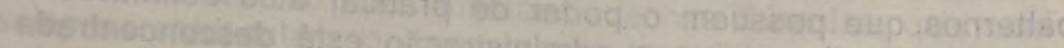

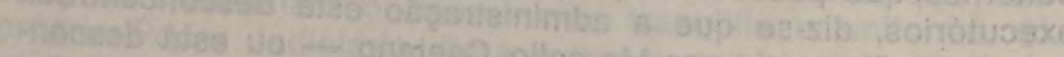

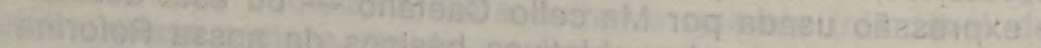

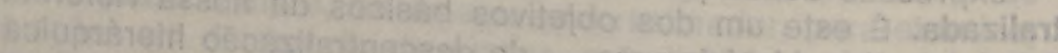

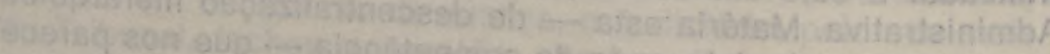

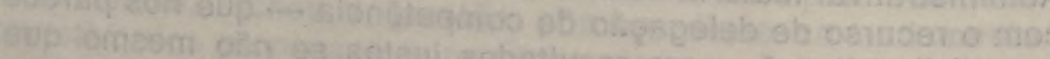

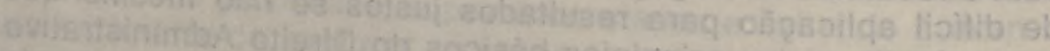

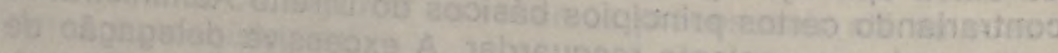

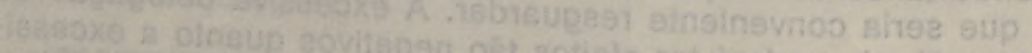

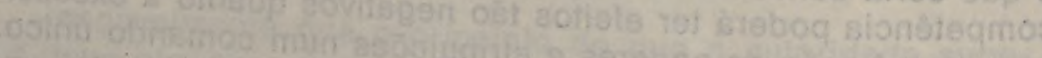

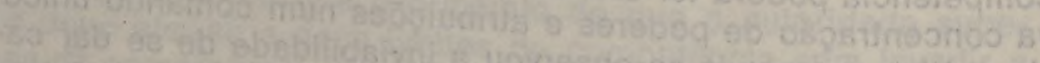

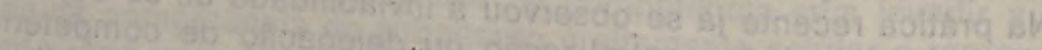

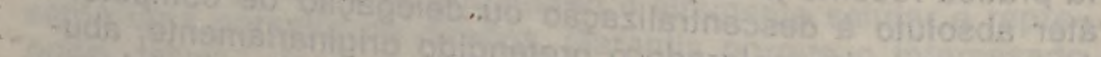

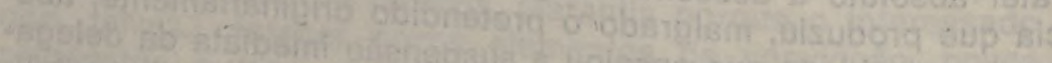

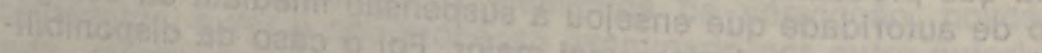

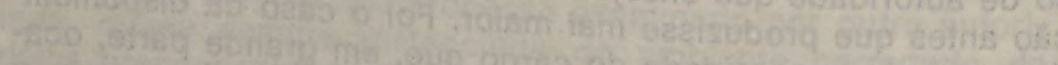

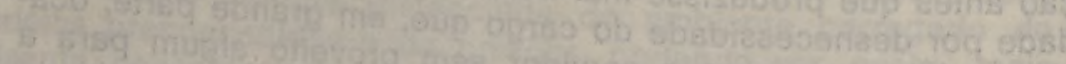

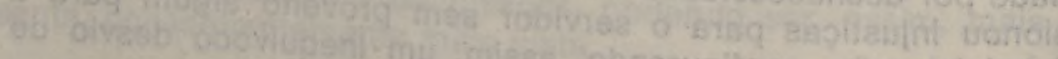

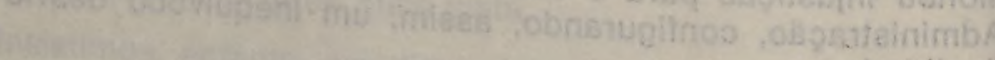
obshiliscil

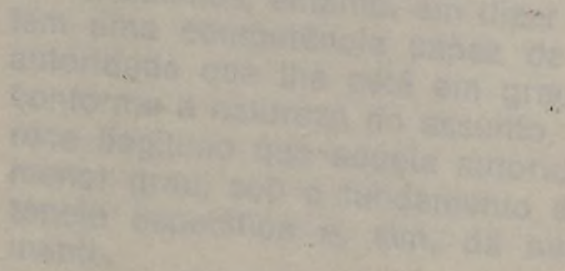

